Michael Lutter, Lukas M. Stratmann and Klaus Jurkschat*

\title{
The tert-butylaminomethyl(mesityl)phosphinic acid ester and formation of its zinc dichloride complex: syntheses and characterization
}

https://doi.org/10.1515/mgmc-2018-0014

Received March 24, 2018; accepted April 25, 2018; previously published online May 22, 2018

Abstract: The syntheses and structures of tertbutylaminomethyl(mesityl)phosphinic acid ethyl ester 2 and its zinc dichloride complex $\mathbf{3}$ are reported. In the solid state, both compounds are dimeric via hydrogen bridges. In the complex $\mathbf{3}$, the phosphinic acid ester $\mathbf{2}$ coordinates the zinc dichloride diastereoselectively.

Keywords: chelate ligand; diastereoselectivity; phosphinic acid ester; phosphorus; zinc.

\section{Introduction}

Diorganophosphinic acids $\mathrm{R}_{2} \mathrm{PO}_{2} \mathrm{H}(\mathrm{R}=$ alkyl, aryl) are a fundamental class of phosphorus compounds. Together with their esters $\mathrm{R}_{2} \mathrm{PO}_{2} \mathrm{R}^{\prime}$ and the corresponding anions $\mathrm{R}_{2} \mathrm{PO}_{2}^{-}$they are rather popular phosphorus-based ligands in both main group and transition metal chemistry. The structural diversity of their metal complexes with a total number of more than 500 solid state structures has recently been reviewed (Carson et al., 2017). To the best of our knowledge, unsymmetrically substituted alkyl(aryl)phosphinic acids and their corresponding derivatives (Korpiun et al., 1968; Onyido et al., 2005) as well as functionally substituted compounds have also received increased interest (Maier, 1992; Kaboudin et al., 2006; Demkowicz et al., 2016). Metal complexes with ligands containing phosphinic acid moieties have been reported as well (Lukeš et al., 2001; Cao et al., 2011; Ševčík et al., 2014). Herein, we present an organoaminomethyl(aryl)phosphinic acid ester and demonstrate its behavior as a chelate ligand towards zinc dichloride.

\footnotetext{
*Corresponding author: Klaus Jurkschat, Lehrstuhl für Anorganische Chemie II, Technische Universität Dortmund, Otto-Hahn-Straße 6, D-44221 Dortmund, Germany, e-mail: klaus.jurkschat@tu-dortmund.de Michael Lutter and Lukas M. Stratmann: Lehrstuhl für Anorganische Chemie II, Technische Universität Dortmund, Otto-Hahn-Straße 6, D-44221 Dortmund, Germany
}

\section{Results and discussion}

The tert-butylaminomethyl(mesityl)phosphinic acid ethyl ester tert- $\mathrm{Bu}(\mathrm{H}) \mathrm{NCH}_{2}\left(2,4,6-\mathrm{Me}_{3} \mathrm{C}_{6} \mathrm{H}_{2}\right) \mathrm{P}(\mathrm{O}) \mathrm{OEt}$, 2, was obtained as its racemate through the amination reaction of compound 1 with an excess of tert-butylamine according to Equation 1.

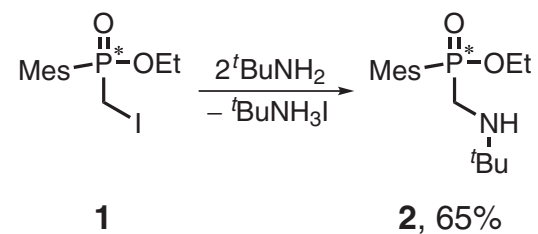

The reaction was performed under elevated pressure at $65^{\circ} \mathrm{C}$ in a teflon-sealed tube. In the course of the reaction, the precipitated white solid was identified by means of the melting point as tert-butylammonium iodide $\left(220^{\circ} \mathrm{C}\right.$, lit. $218-220^{\circ} \mathrm{C}$ (Herrschaft and Hartl, 1989). After a reaction time of $96 \mathrm{~h}$, the conversion was complete and the reaction mixture was purified by performing acid base extraction. Compound $\mathbf{2}$ was obtained as a white solid material with a melting point of $67^{\circ} \mathrm{C} . \mathrm{A}^{31} \mathrm{P}\left\{{ }^{1} \mathrm{H}\right\}$ NMR spectrum of its solution in $\mathrm{CDCl}_{3}$ showed a singlet resonance at $\delta 44.6 \mathrm{ppm}$ that was low field shifted as compared with the signal of compound $\mathbf{1}\left[\delta 38.0 \mathrm{ppm}, \mathrm{CDCl}_{3}\right.$ (Lutter and Jurkschat, 2018)]. A ${ }^{1} \mathrm{H}$ NMR spectrum revealed the characteristic singlet resonance of the tert-butyl protons at $\delta 0.89 \mathrm{ppm}$. An electrospray ionization (ESI) mass spectrum showed three mass clusters which were assigned to $[2 \quad 2+\mathrm{Na}]^{+}(m / z=617.3),[\mathbf{2}+\mathrm{Na}]^{+}(m / z=320.1)$ and $[\mathbf{2}+\mathrm{H}]^{+}$ $(\mathrm{m} / z=298.1)$. From its solution in acetone, colorless block-shaped crystals of compound $\mathbf{2}$ were obtained; the compound crystallized in the monoclinic space group $P 2_{1} / n$ with four molecules in the asymmetric unit (Figure 1). Hydrogen bond distances and angles are given in the Figure caption. Crystallographic data are given in Table 1 .

There exists a hydrogen bond (N1-H1 ‥ 01 3.001(3) A, $\left.170(3)^{\circ}\right)$ between the PO and $\mathrm{NH}$ functional groups connecting two molecules. In the graph set analysis according to Etter and Bernstein (Bernstein et al., 1990, 1995a,b; Etter, 1990, 1991; Etter et al., 1990; Bernstein, 1991) the unitary elemental graph set is $\mathrm{N}_{1}=R_{2}^{2}(10)$, which is a 


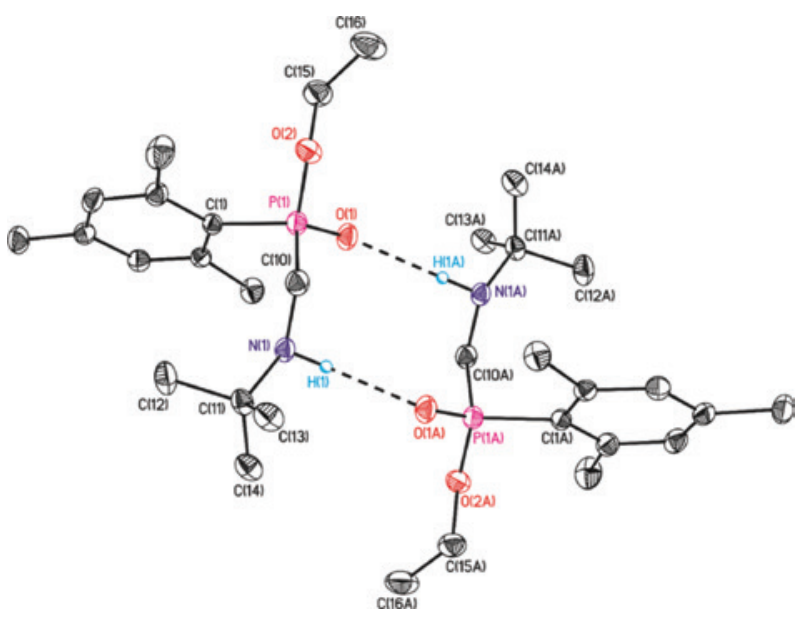

Figure 1: The displacement ellipsoid ( $30 \%$ probability level) plot and the numbering scheme of the dimeric structure of compound 2 in the crystal.

$\mathrm{C}-\mathrm{H}$ hydrogen atoms are omitted. Hydrogen bond distance $[\AA \AA]$ and angle $\left[^{\circ}\right]$ : $\mathrm{N}(1)-\mathrm{H}(1) \cdots \mathrm{O}(1 \mathrm{~A}) 3.001(3), 170(3)$. Symmetry code: (A) 1-x, $1-y, 1-z$. ten-membered ring motif. In order to investigate the properties of compound $\mathbf{2}$ as a chelating ligand, the latter was reacted with zinc chloride in acetone according to Equation 2.<smiles>CCOP(C)(=O)CNCBr</smiles>

After the slow evaporation of the solvent, some colorless plate-shaped crystals of compound 3 were obtained. The washed (iso-hexane) and dried crystalline material of compound 3 was used for the acquisition of all analytical data.

A ${ }^{31} \mathrm{P}\left\{{ }^{1} \mathrm{H}\right\}$ NMR spectrum $\left(\mathrm{CDCl}_{3}\right)$ showed one broad singlet resonance at $\delta 54.2 \mathrm{ppm}\left(\mathrm{v}_{1 / 2}=78.6 \mathrm{~Hz}\right)$, which is low field shifted $(9.6 \mathrm{ppm})$ as compared with the signal of compound 2 . The line width of the signal likely

Table 1: Crystallographic data for compounds $\mathbf{2}$ and $\mathbf{3 .}$

\begin{tabular}{|c|c|c|}
\hline & 2 & 3 \\
\hline Empirical formula & $\mathrm{C}_{16} \mathrm{H}_{28} \mathrm{NO}_{2} \mathrm{P}$ & $\mathrm{C}_{16} \mathrm{H}_{28} \mathrm{Cl}_{2} \mathrm{NO}_{2} \mathrm{PZn}$ \\
\hline Formula mass $\left[\mathrm{g} \cdot \mathrm{mol}^{-1}\right]$ & 297.36 & 433.63 \\
\hline $\mathrm{T}[\mathrm{K}]$ & $173(2)$ & $173(2)$ \\
\hline$\lambda[\AA ̊]$ & 0.71073 & 1.54178 \\
\hline Crystal system & Monoclinic & Monoclinic \\
\hline Space group & $P 2_{1} / n$ & $P 2_{1} / c$ \\
\hline a $[\AA ̊]$ & $10.6794(12)$ & $11.9168(10)$ \\
\hline $\mathrm{b}[\AA ̊]$ & $11.9199(13)$ & $17.6511(14)$ \\
\hline$c[\AA]$ & $14.0925(16)$ & $19.9614(18)$ \\
\hline$\alpha\left[^{\circ}\right]$ & 90 & 90 \\
\hline$\beta\left[^{\circ}\right]$ & $105.742(12)$ & $102.971(9)$ \\
\hline$\gamma\left[^{\circ}\right]$ & 90 & 90 \\
\hline $\mathrm{V}\left[\AA^{3}\right]$ & $1726.7(3)$ & $4091.6(6)$ \\
\hline Z & 4 & 8 \\
\hline$\rho_{\text {calcd. }}\left[\mathrm{g} \cdot \mathrm{cm}^{-3}\right]$ & 1.144 & 1.408 \\
\hline$\mu\left[\mathrm{mm}^{-1}\right]$ & 0.161 & 4.866 \\
\hline$F(000)$ & 648 & 1808 \\
\hline Crystal size $[\mathrm{mm}]$ & $0.220 \cdot 0.160 \cdot 0.130$ & $0.160 \cdot 0.120 \cdot 0.030$ \\
\hline$\theta$ range $\left[^{\circ}\right]$ & $2.617-27.499$ & $3.381-68.981$ \\
\hline \multirow{3}{*}{ Index ranges } & $-13 \leq h \leq 13$ & $-14 \leq h \leq 13$ \\
\hline & $-15 \leq k \leq 15$ & $-20 \leq k \leq 21$ \\
\hline & $-17 \leq \mathrm{I} \leq 18$ & $-19 \leq \mathrm{l} \leq 24$ \\
\hline No. of reflections collected & 14583 & 29972 \\
\hline No. of independent reflections $/ R_{\text {int }}$ & $3888 / 0.0769$ & $7611 / 0.0637$ \\
\hline Completeness of $\theta_{\max }[\%]$ & 99.9 & 100.0 \\
\hline Data/Restrains/parameters & $3888 / 1 / 192$ & $7611 / 2 / 437$ \\
\hline $\mathrm{GoF}\left(\mathrm{F}^{2}\right)$ & 0.927 & 1.551 \\
\hline$R_{1}(F)[I>2 \sigma(I)]$ & 0.0614 & 0.0635 \\
\hline $\mathrm{wR}_{2}\left(\mathrm{~F}^{2}\right)$ (all data) & 0.1615 & 0.1953 \\
\hline Largest difference peak/hole $\left[\mathrm{e} \AA^{-3}\right]$ & $0.253 /-0.362$ & $1.561 /-1.090$ \\
\hline
\end{tabular}




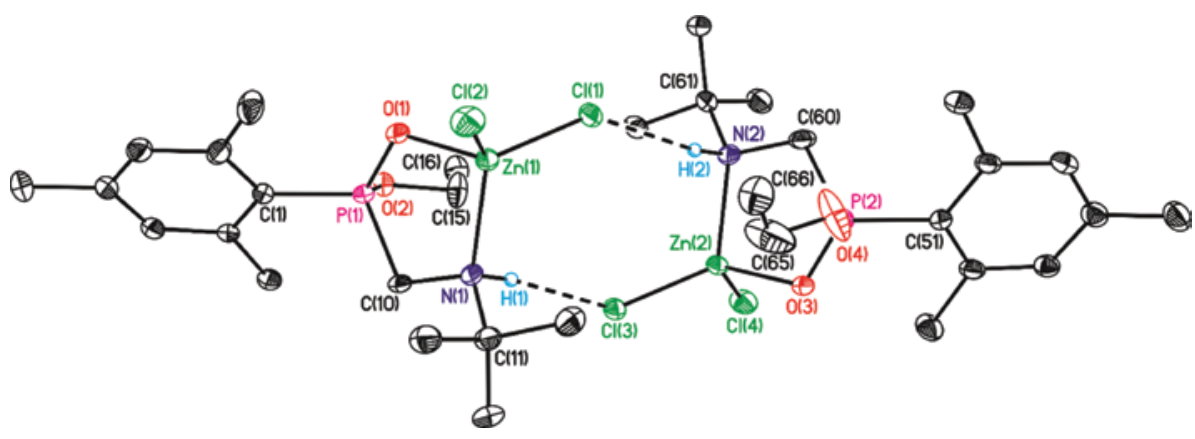

Figure 2: The displacement ellipsoid (30\% probability level) plot and the numbering scheme of the dimeric structure of compound 3 in the crystal.

The C-H hydrogen atoms are omitted. Selected interatomic distances [Å]: $\mathrm{Zn}(1)-\mathrm{Cl}(1)$ 2.2417(12), $\mathrm{Zn}(1)-\mathrm{Cl}(2)$ 2.2035(13), $\mathrm{Zn}(1)-0$ (1) 2.002(3), $\mathrm{Zn}(1)-\mathrm{N}(1)$ 2.113(3), $\mathrm{Zn}(2)-\mathrm{Cl}(3)$ 2.2346(12), $\mathrm{Zn}(2)-\mathrm{Cl}(4)$ 2.2033(13), $\mathrm{Zn}(2)-\mathrm{O}$ (3) 2.017(3), $\mathrm{Zn}(2)-\mathrm{N}(2)$ 2.105(3). Selected interatomic angles [']: Cl(1)-Zn(1)-Cl(2) 116.95(5), Cl(1)-Zn(1)-N(1) 107.64(11), Cl(1)-Zn(1)-O(1) 107.50(10), Cl(2)-Zn(1)-N(1) 121.71(11), Cl(2)-Zn(1)-O(1) 111.14(10), $\mathrm{N}(1)-\mathrm{Zn}(1)-\mathrm{O}(1)$ 87.44(13), Cl(3)-Zn(2)-Cl(4) 116.18(5), Cl(3)-Zn(2)-N(2) 110.34(11), Cl(3)-Zn(2)-O(3) 110.42(10), Cl(4)-Zn(2)-N(2) 119.88(11), $\mathrm{Cl}(4)-\mathrm{Zn}(2)-\mathrm{O}(3)$ 108.44(11), N(2)-Zn(2)-O(3) 87.66(14). Hydrogen bond distances [Å] and angles [०]: N(1)-H(1) $\ldots \mathrm{Cl} 33.502(4), 173(6)$; $\mathrm{N}(2)-\mathrm{H}(2) \cdots \mathrm{Cl} 13.470(4), 171(5)$.

indicates the kinetic lability of the complex 3 in solution and an equilibrium $\mathbf{2}+\mathrm{ZnCl}_{2} \rightleftharpoons \mathbf{3}$, which is on the onset of becoming slow on the NMR time scale. Alternatively, an epimerization induced by the rupture of either the $\mathrm{P}=\mathrm{O} \rightarrow \mathrm{Zn}$ or $\mathrm{N} \rightarrow \mathrm{Zn}$ coordination could also account for the broadening of the ${ }^{31} \mathrm{P}$ NMR resonance. However, this was not investigated in further detail. A ${ }^{1} \mathrm{H}$ NMR spectrum showed an ABX pattern for the $\mathrm{PCH}_{2} \mathrm{~N}$ methylene protons at $\delta 3.13 / 3.39 \mathrm{ppm}\left(U_{\mathrm{AB}}=14.8 \mathrm{~Hz}, J_{\mathrm{AX}}=9.5 \mathrm{~Hz}\right.$, $J_{\mathrm{BX}}=6.4 \mathrm{~Hz}$ ).

An ESI mass spectrum (positive mode) showed four mass peaks at $m / z=320.17,298.19,213.10$, and 185.07, which are assigned to the cationic species $[\mathbf{2}+\mathrm{Na}]^{+},[\mathbf{2}+\mathrm{H}]^{+}$, $[\mathrm{MesPH}(\mathrm{O})(\mathrm{OEt})+\mathrm{H}]^{+}$, and $\left[\mathrm{MesP}(\mathrm{OH})_{2}+\mathrm{H}\right]^{+}$, respectively. The absence of the mass peak of the zinc complex 3 indicates that a positively charged zinc complex is not stable under the experimental ESI MS conditions employed.

From its solution in acetone, compound $\mathbf{3}$ precipitated as colorless plate-shaped crystals. The compound crystallized in the monoclinic space group $P 2_{1} / c$ with eight molecules in the asymmetric unit (Figure 2). The hydrogen bond distances and angles are given in the figure caption. Crystallographic data are given in Table 1.

The $\mathrm{Zn}(1)$ and $\mathrm{Zn}(2)$ atoms are four-coordinated by $\mathrm{Cl}(1), \mathrm{Cl}(2), \mathrm{O}(1)$ and $\mathrm{N}(1)$, and $\mathrm{Cl}(3), \mathrm{Cl}(4), \mathrm{O}(3)$ and $\mathrm{N}(2)$, respectively, at distances of 2.2417(12), 2.2035(13), 2.002(3), and 2.113(3) ̊̊, respectively, and 2.2346(12), 2.2033(13), 2.017(3) and 2.105(3) A, respectively. The $\mathrm{Cl}(1)$ and $\mathrm{Cl}(3)$ atoms are involved in the hydrogen bonds (N1-H1 $\cdots \mathrm{Cl} 3$ 3.502(4), N2-H2 ‥ Cl1 3.469(4) ̊). Consequently, the Zn(1)$\mathrm{Cl}(1)$ and $\mathrm{Zn}(2)-\mathrm{Cl}(3)$ distances are slightly longer than the $\mathrm{Zn}(2)-\mathrm{Cl}(2)$ and $\mathrm{Zn}(2)-\mathrm{Cl}(4)$ distances. The zinc atom exhibits a distorted tetrahedral environment with angles ranging between $121.71(11)^{\circ}(\mathrm{Cl} 2-\mathrm{Zn} 1-\mathrm{N} 1)$ and $87.44(13)^{\circ}$ (N1-Zn1-O1).

The graph set analysis of compound 3 gives two finite patterns on the unitary elemental level $\left(\mathrm{N}_{1}=\mathrm{DD}\right)$. The pattern on the binary elemental level is an eight-membered ring and can be described with $\mathrm{N}_{2}(\mathrm{a}, \mathrm{b})=R_{2}^{2}(8)$. Considering this eight-membered ring, the $\mathrm{Cl}(2)$ and $\mathrm{Cl}(4)$ atoms are trans, as are the five-membered $\mathrm{Zn}(1)-\mathrm{N}(1)-\mathrm{C}(10)-\mathrm{P}(1)-$ $\mathrm{O}(1)$ and $\mathrm{Zn}(2)-\mathrm{N}(2)-\mathrm{C}(60)-\mathrm{P}(2)-\mathrm{O}(2)$ chelate rings.

\section{Conclusion}

When coordinated with the zinc dichloride, the nitrogen atom of tert-butylaminomethyl(mesityl)phosphinic acid ethyl ester $\mathbf{2}$ is a stereogenic center, in addition to the one at the phosphorus atom. This means that two diastereomers are possible for the resulting zinc dichloride complex 3. However, apparently, the complexation proceeds diastereoselectively. Only one diastereomer was observed in the solid state. Although this has been established only for the single crystal actually measured, it is rather likely to hold also for the bulk material. The diastereomer with the tert-butyl substituents in cis-position should be less favored. This phenomenon needs to be evaluated by further experiments as well as DFT calculations. Nevertheless, the results demonstrate, to some extent, the high potential the title compound and related derivatives hold for such stereoselective reactions. In addition, the $\mathrm{N}-\mathrm{H}$ function in both the ester $\mathbf{2}$ and the zinc dichloride complex $\mathbf{3}$ is involved in the hydrogen bridges and creates supramolecular structures. 


\section{Experimental}

\section{Crystallography}

Intensity data for compound $\mathbf{2}$ were collected on an XcaliburS CCD diffractometer (Oxford Diffraction, Oxford, England) using Mo-K $\alpha$ radiation at 173(1) $\mathrm{K}$ with an Oxford Cryostream. The intensity data for compound 3 were collected on an APEX-II CCD diffractometer (Bruker Corporation, Billerica, MA, USA) using $\mathrm{Cu}-\mathrm{K} \alpha$ radiation at $100 \mathrm{~K}$.

The structures were solved with direct methods using SHELXS-97 (compound 2) or SHELXS-2014/7 (compound 3) (Sheldrick, 2008, 2015) and refinements were carried out against $F 2$ by using SHELXL-2014/7 (Sheldrick, 2008, 2015). The C-H hydrogen atoms were positioned with idealized geometry and refined using a riding model. All non-hydrogen atoms were refined using anisotropic displacement parameters. The NH protons of all compounds were located in the difference Fourier map and refined freely; the N-H distances were restrained to a fix value.

CCDC-1831583 (2) and CCDC-1831584 (3) contain the supplementary crystallographic data for this paper. This data can be obtained free of charge from The Cambridge Crystallographic Data Centre via www.ccdc.cam.ac.uk/data_request/cif. For the decimal rounding of numerical parameters and su values, the rules of IUCr have been employed (Clegg, 2003). All Figures were generated using ORTEP III (Farrugia, 1997; Farrugia, 2012) visualization software. The graph sets were calculated using cthe alculation routine of Mercury (Macrae et al., 2006, 2008).

\section{General}

Solvents, including NMR solvents, were purified by distillation from the appropriate drying agents under argon and stored over molecular sieves. The NMR spectra were recorded at room temperature on a Bruker AV DPX 300. NMR chemical shifts were given in ppm and were referenced to $\mathrm{Me}_{4} \mathrm{Si}\left({ }^{1} \mathrm{H},{ }^{13} \mathrm{C}\right.$ ) (using residual solvent signal: $\mathrm{CDCl}_{3}$ $\left.{ }^{1} \mathrm{H} 7.27 \mathrm{ppm},{ }^{13} \mathrm{C} 77.0 \mathrm{ppm}\right)$ and $\mathrm{H}_{3} \mathrm{PO}_{4}\left(85 \%,{ }^{31} \mathrm{P}\right)$. Elemental analyses were performed on a LECO-CHNS-932 analyzer (LECO Corporation, St. Joseph, MI, USA). The samples were weighted at air. The uncorrected melting points were measured on a Büchi M-560 (Büchi Labortechnik GmbH, Essen, Germany). The electrospray mass spectra were recorded with a Thermoquest-Finnigan instrument (Scientific Instrument Services, Ringoes, NJ, USA). The concentration was $0.1 \mathrm{mg} /$ $\mathrm{mL}$ with a flow rate of $10 \mu \mathrm{L} / \mathrm{min}$. The experimental isotopic pattern matched the theoretical ones. IR spectra $\left(\mathrm{cm}^{-1}\right)$ were measured on a Perkin Elmer Spectrum Two (ATR, PerkinElmer, Inc., Waltham, MA, USA). The synthesis of compound 1 has already been published. (Lutter and Jurkschat, 2018). The tert-butyl amine (98\%) was purchased (abcr $\mathrm{GmbH}$, Karlsruhe, Germany). The latter was dried $\left(\mathrm{CaH}_{2}\right)$ and distilled prior before use. The zinc chloride (97\%) was purchased (abcr GmbH, Karlsruhe, Germany) and used without further purification.

\section{$\mathrm{N}$-(tert-butyl)aminomethyl(mesityl)phosphinic acid ethyl ester (2)}

A stirring solution of iodomethylmesitylphosphinic acid ethylester (1) $(3.520 \mathrm{~g}, 10.0 \mathrm{mmol})$ in freshly distilled tert-butyl amine $(10.5 \mathrm{~mL}$,
$100.0 \mathrm{mmol})$ was heated $\left(65^{\circ} \mathrm{C}\right)$ for $96 \mathrm{~h}$ under pressure. The resulting solid was filtered, washed with cold iso-hexane, dried and identified as tert-butylammoninium iodide by means of the melting point $\left(220^{\circ} \mathrm{C}\right)$. The volatiles of the filtrate were removed under reduced pressure. The residue was dissolved in dichloromethane $(10 \mathrm{~mL})$, acidified with diluted hydrochloric acid (10 $\mathrm{mL}, 1 \mathrm{M})$, and extracted with water $(3 \times 10 \mathrm{~mL})$. The combined aqueous phases were treated with a diluted sodium hydroxide solution $(1 \mathrm{M})$ to $\mathrm{pH}>10$ and extracted with dichloromethane $(3 \times 10 \mathrm{~mL})$. After drying the combined organic phases over magnesium sulphate and performing filtration, the volatiles of the resulting solution were removed under reduced pressure. Compound 2 (1.930 g, $6.5 \mathrm{mmol}, 65 \%$ ) was obtained as a colorless block-shaped crystalline solid with a melting point of $67^{\circ} \mathrm{C}$.

${ }^{1} \mathrm{H}$ NMR: (300.13 MHz, $\left.\mathrm{CDCl}_{3}, 298 \mathrm{~K}, 16 \mathrm{scans}\right): \delta 6.76$ (d, ${ }^{4} J\left({ }^{1} \mathrm{H}-\right.$ $\left.\left.{ }^{31} \mathrm{P}\right)=3.7 \mathrm{~Hz}, 2 \mathrm{H}, \mathrm{C}_{m} \mathrm{H}\right)$, 4.15-4.02 (complex pattern, $1 \mathrm{H}, \mathrm{CH}_{2} \mathrm{CH}_{3}$ ), 3.89-3.76 (complex pattern, $1 \mathrm{H}, \mathrm{CH}_{2} \mathrm{CH}_{3}$ ), 3.02-2.85 (complex pattern, $\left.2 \mathrm{H}, \mathrm{PCH}_{2} \mathrm{~N}\right), 2.51\left(\mathrm{~s}, 6 \mathrm{H}, \mathrm{C}_{o} \mathrm{CH}_{3}\right), 2.14\left(\mathrm{~s}, 3 \mathrm{H}, \mathrm{C}_{p} \mathrm{CH}_{3}\right), 1.20$ (t, $\left.{ }^{3}\left({ }^{1} \mathrm{H}-{ }^{-1} \mathrm{H}\right)=7.1 \mathrm{~Hz}, 3 \mathrm{H}, \mathrm{CH}_{2} \mathrm{CH}_{3}\right), 0.89$ (s, 9H, C $\left.\left(\mathrm{CH}_{3}\right)_{3}\right) .{ }^{13} \mathrm{C}\left\{{ }^{1} \mathrm{H}\right\}$ NMR: (75.48 MHz, $\left.\mathrm{CDCl}_{3}, 298 \mathrm{~K}, 640 \mathrm{scans}\right): \delta 143.1\left(\mathrm{~d},{ }^{2}\left({ }^{13} \mathrm{C}-{ }^{31} \mathrm{P}\right)=11.2 \mathrm{~Hz}\right.$, $\left.\mathrm{C}_{o}\right), 141.2\left(\mathrm{~d},{ }^{4} J\left({ }^{13} \mathrm{C}{ }^{31} \mathrm{P}\right)=2.8 \mathrm{~Hz}, \mathrm{C}_{p}\right), 130.3\left(\mathrm{~d},{ }^{3} \mathrm{~J}\left({ }^{13} \mathrm{C}{ }^{31} \mathrm{P}\right)=12.7 \mathrm{~Hz}, \mathrm{C}_{\mathrm{m}}\right)$, $123.6\left(\mathrm{~d},{ }^{1}{ }^{13}\left({ }^{31}{ }^{31} \mathrm{P}\right)=120.4 \mathrm{~Hz}, \mathrm{C}_{i}\right), 60.0\left(\mathrm{~d},{ }^{2}{ }^{13}\left({ }^{13}{ }^{31} \mathrm{P}\right)=6.5 \mathrm{~Hz}, \mathrm{CH}_{2} \mathrm{CH}_{3}\right)$, $50.3\left(\mathrm{~d},{ }^{3} J\left({ }^{13} \mathrm{C} \cdot{ }^{31} \mathrm{P}\right)=14.6 \mathrm{~Hz}, C\left(\mathrm{CH}_{3}\right)_{3}\right), 43.0\left(\mathrm{~d},{ }^{1}{ }^{13}\left({ }^{13}{ }^{31} \mathrm{P}\right)=110.1 \mathrm{~Hz}\right.$, $\left.\mathrm{PCH}_{2} \mathrm{~N}\right), 28.1\left(\mathrm{~s}, \mathrm{C}\left(\mathrm{CH}_{3}\right)_{3}\right), 22.9\left(\mathrm{~d},{ }^{3} \mathrm{~J}^{13} \mathrm{C}^{31} \mathrm{P}\right)=2.3 \mathrm{~Hz}$, ortho $\left.-\mathrm{C}_{0} \mathrm{CH}_{3}\right), 20.6$ $\left(\mathrm{d},{ }^{5}\left({ }^{13} \mathrm{C}-{ }^{31} \mathrm{P}\right)=0.9 \mathrm{~Hz}\right.$, para $\left.-\mathrm{C}_{p} \mathrm{CH}_{3}\right), 16.1\left(\mathrm{~d},{ }^{3} \mathrm{~J}\left({ }^{13} \mathrm{C}{ }^{31} \mathrm{P}\right)=6.4 \mathrm{~Hz}, \mathrm{CH}_{2} \mathrm{CH}_{3}\right)$. ${ }^{31} \mathrm{P}\left\{{ }^{1} \mathrm{H}\right\}$ NMR: (121.50 MHz, CDCl $, 298 \mathrm{~K}, 128$ scans): $\delta=44.6$ (s, ${ }^{1}\left({ }^{31} \mathrm{P}-\right.$ $\left.\left.{ }^{13} \mathrm{C}\right)=120.3 \mathrm{~Hz},{ }^{1}{ }^{3}\left({ }^{31} \mathrm{P}-{ }^{13} \mathrm{C}\right)=110.1 \mathrm{~Hz}\right)$. Elemental analysis: calculated (found) for $\mathrm{C}_{16} \mathrm{H}_{28} \mathrm{NO}_{2} \mathrm{P} 64.6(64.8) \% \mathrm{C}, 9.5(9.3) \% \mathrm{H}, 4.7(4.7) \% \mathrm{~N}$. ESI MS: (acetonitrile, $m / z$, positive mode): $617.3[22+\mathrm{Na}]^{+}, 320.1[2+\mathrm{Na}]^{+}$, $298.1[2+\mathrm{H}]^{+}$. IR: $\left(\mathrm{cm}^{-1}\right): v_{\mathrm{N}-\mathrm{H}} 3288, v_{\mathrm{P}=\mathrm{O}} 1212$.

\section{$\mathrm{N}$-(tert-butyl)aminomethyl(mesityl)phosphinic acid ethyl ester zinc chloride complex (3)}

To a solution of the secondary amine $2(0.120 \mathrm{~g}, 0.4 \mathrm{mmol})$ in acetone $(5 \mathrm{~mL})$ zinc chloride $(0.550 \mathrm{~g}, 0.4 \mathrm{mmol})$ was added. After the slow evaporation of the solvent, the complex 3 was obtained as a colorless plate-shaped crystalline solid ( $0.164 \mathrm{~g}, 0.38 \mathrm{mmol}, 95 \%)$ with a melting point of $180^{\circ} \mathrm{C}$ (decomposition).

${ }^{1} \mathrm{H}$ NMR: (300.13 MHz, $\mathrm{CDCl}_{3}, 297 \mathrm{~K}, 16$ scans): $\delta 6.97\left(\mathrm{~d},{ }^{4} J\left({ }^{1} \mathrm{H}-\right.\right.$ $\left.{ }^{31} \mathrm{P}\right)=4.5 \mathrm{~Hz}, 2 \mathrm{H}, \mathrm{C}_{m} \mathrm{H}$ ), 4.34-3.97 (complex pattern, $2 \mathrm{H}, \mathrm{CH}_{2} \mathrm{CH}_{3}$ ), $3.39\left(\right.$ ABX pattern, $\left.{ }^{2} J\left({ }^{1} \mathrm{H}-{ }^{1} \mathrm{H}\right)=14.8 \mathrm{~Hz},{ }^{2} J\left({ }^{1} \mathrm{H}{ }^{31} \mathrm{P}\right)=9.5 \mathrm{~Hz}, 1 \mathrm{H}, \mathrm{PCH}_{2} \mathrm{~N}\right)$, $3.13\left(\mathrm{ABX}\right.$ pattern, $\left.{ }^{2} J\left({ }^{1} \mathrm{H}-{ }^{-1} \mathrm{H}\right)=14.8 \mathrm{~Hz},{ }^{2}{ }^{1}\left({ }^{1} \mathrm{H}^{31} \mathrm{P}\right)=6.4 \mathrm{~Hz}, 1 \mathrm{H}, \mathrm{PCH}_{2} \mathrm{~N}\right)$, $2.59\left(\mathrm{~d},{ }^{4} \mathrm{~J}\left({ }^{1} \mathrm{H}{ }^{31} \mathrm{P}\right)=1.2 \mathrm{~Hz}, 6 \mathrm{H}, \mathrm{C}_{o} \mathrm{CH}_{3}\right), 2.32\left(\mathrm{~s}, 3 \mathrm{H}, \mathrm{C}_{p} \mathrm{CH}_{3}\right), 1.38(\mathrm{~s}$, 9H, $\left.\mathrm{C}\left(\mathrm{CH}_{3}\right)_{3}\right), 1.36\left(\mathrm{t},{ }^{3} \mathrm{~J}\left({ }^{1} \mathrm{H}-{ }^{-1} \mathrm{H}\right)=7.1 \mathrm{~Hz}, 3 \mathrm{H}, \mathrm{CH}_{2} \mathrm{CH}_{3}\right),{ }^{13} \mathrm{C}\left\{{ }^{1} \mathrm{H}\right\} \mathrm{NMR}$ : (75.47 MHz, $\mathrm{CDCl}_{3}, 297 \mathrm{~K}, 640$ scans): $\delta 144.7\left(\mathrm{~d},{ }^{4} J\left({ }^{13} \mathrm{C}{ }^{31} \mathrm{P}\right)=2.8 \mathrm{~Hz}\right.$, $\left.\mathrm{C}_{p}\right), 144.1\left(\mathrm{~d},{ }^{2} \mathrm{~J}\left({ }^{13} \mathrm{C}{ }^{31} \mathrm{P}\right)=12.7 \mathrm{~Hz}, \mathrm{C}_{o}\right), 131.5\left(\mathrm{~d},{ }^{3} \mathrm{~J}\left({ }^{13} \mathrm{C}-{ }^{31} \mathrm{P}\right)=14.1 \mathrm{~Hz}, \mathrm{C}_{m}\right)$, $118.5\left(\mathrm{~d},{ }^{1} \mathrm{~J}\left({ }^{13} \mathrm{C}-{ }^{31} \mathrm{P}\right)=131.4 \mathrm{~Hz}, \mathrm{C}_{i}\right), 63.6\left(\mathrm{~d},{ }^{2} \mathrm{~J}\left({ }^{13} \mathrm{C}{ }^{31} \mathrm{P}\right)=6.7 \mathrm{~Hz}, \mathrm{CH}_{2} \mathrm{CH}_{3}\right)$, $56.5\left(\mathrm{~d},{ }^{3}\left({ }^{13} \mathrm{C}-{ }^{31} \mathrm{P}\right)=9.9 \mathrm{~Hz}, \mathrm{C}\left(\mathrm{CH}_{3}\right)_{3}\right), 42.0\left(\mathrm{~d},{ }^{1} J\left({ }^{13} \mathrm{C}-{ }^{31} \mathrm{P}\right)=102.2 \mathrm{~Hz}\right.$, $\left.\mathrm{PCH}_{2} \mathrm{~N}\right), 27.9\left(\mathrm{~s}, \mathrm{C}\left(\mathrm{CH}_{3}\right)_{3}\right), 23.3\left(\mathrm{~d},{ }^{3} \mathrm{~J}\left({ }^{13} \mathrm{C} \cdot{ }^{31} \mathrm{P}\right)=3.0 \mathrm{~Hz}, \mathrm{CC}_{\mathrm{o}} \mathrm{H}_{3}\right), 21.2(\mathrm{~d}$, $\left.{ }^{5}\left({ }^{13} \mathrm{C}^{31} \mathrm{P}\right)=0.8 \mathrm{~Hz}, \mathrm{C}_{p} \mathrm{CH}_{3}\right), 16.1\left(\mathrm{~d},{ }^{3} \mathrm{~J}\left({ }^{13} \mathrm{C} \cdot{ }^{31} \mathrm{P}\right)=6.7 \mathrm{~Hz}, \mathrm{CH}_{2} \mathrm{CH}_{3}\right) .{ }^{31} \mathrm{P}\left\{{ }^{1} \mathrm{H}\right\}$ NMR: (121.50 MHz, $\left.\mathrm{CDCl}_{3}, 297 \mathrm{~K}, 128 \mathrm{scans}\right): \delta=54.2\left(\mathrm{~s}, \mathrm{v}_{1 / 2}=78.6 \mathrm{~Hz}\right)$. Elemental analysis: calculated (material from 1st synthesis found, material from 2nd synthesis found) for $\mathrm{C}_{16} \mathrm{H}_{28} \mathrm{Cl}_{2} \mathrm{NO}_{2} \mathrm{PZn} 44.3$ (43.2, 43.5)\% C, $6.5(6.5,6.5) \% \mathrm{H}, 3.2(3.1,3.1) \% \mathrm{~N}$. ESI MS: (material from 2nd synthesis, acetonitrile + water $1: 1+0.1 \%$ trifluoro acetic acid, $m / z$, positive mode): $320.17[\mathbf{2}+\mathrm{Na}]^{+}, 298.19[\mathbf{2}+\mathrm{H}]^{+}, 213.10$ $[\mathrm{MesPH}(\mathrm{O})(\mathrm{OEt})+\mathrm{H}]^{+}, 185.07\left[\mathrm{MesP}(\mathrm{OH})_{2}+\mathrm{H}\right]^{+}$. ESI MS: (material from 2nd synthesis, acetonitrile, $\mathrm{m} / \mathrm{z}$, positive mode): 595.38 [2 $2+\mathrm{H}]^{+}, 298.19\left[2+\mathrm{H}^{+}\right.$. IR: $\left(\mathrm{cm}^{-1}\right): v_{\mathrm{N}-\mathrm{H}} 3197, v_{\mathrm{P}=0} 1150$. 


\section{References}

Bernstein, J. Polymorphism of L-glutamic acid: decoding the $\alpha-\beta$ phase relationship via graph-set analysis. Acta Cryst. 1991, B47, 1004-1010.

Bernstein, J.; Etter, M. C.; MacDonald, J. C. Decoding hydrogen-bond patterns. The case of iminodiacetic acid. J. Chem. Soc., Perkin Trans. 2 1990, 5, 695.

Bernstein, J.; Davis, R. E.; Shimoni, L.; Chang, N.-L. Patterns in hydrogen bonding: functionality and graph set analysis in crystals. Angew. Chem. Int. Ed. 1995a, 34, 1555-1573.

Bernstein, J.; Shimoni, L.; Davis, R. E.; Chang, N.-L. Muster aus H-Brücken: ihre Funktionalität und ihre graphentheoretische Analyse in Kristallen. Angew. Chem. 1995b, 107, 1689-1708.

Cao, Z.; Zhang, Y.; Song, P.; Cai, Y.; Guo, Q.; Fang, Z.; Peng, M. A novel zinc chelate complex containing both phosphorus and nitrogen for improving the flame retardancy of low density polyethylene. J. Anal. Appl. Pyrolysis 2011, 92, 339-346.

Carson, I.; Healy, M. R.; Doidge, E. D.; Love, J. B.; Morrison, C. A.; Tasker, P. A. Metal-binding motifs of alkyl and aryl phosphinates; versatile mono and polynucleating ligands. Coord. Chem. Rev. 2017, 335, 150-171.

Clegg, W. Some guidelines for publishing SHELXL-generated CIF results in Acta Crystallographica. decimal rounding. Acta Cryst. 2003, E59, e2-e5.

Demkowicz, S.; Rachon, J.; Dasko, M.; Kozak, W. Selected organophosphorus compounds with biological activity. Applications in medicine. RSC Adv. 2016, 6, 7101-7112.

Etter, M. C. Encoding and decoding hydrogen-bond patterns of organic compounds. Acc. Chem. Res. 1990, 23, 120-126.

Etter, M. C. Hydrogen bonds as design elements in organic chemistry. J. Phys. Chem. 1991, 95, 4601-4610.

Etter, M. C.; MacDonald, J. C.; Bernstein, J. Graph-set analysis of hydrogen-bond patterns in organic crystals. Acta Cryst. 1990, B46, 256-262.

Farrugia, L. J. ORTEP -3 for windows - a version of ORTEP-III with a graphical user interface (GUI). J. Appl. Cryst. 1997, 30, 565.

Farrugia, L. J. WinGX and ORTEP for windows: an update. J. Appl. Cryst. 2012, 45, 849-854.

Herrschaft, G.; Hartl, H. Das isomerenpaar tert-butylammoniumiodid und tetramethylammoniumiodid. Acta Cryst. 1989, C45, 1021-1024.
Kaboudin, B.; Haghighat, H.; Yokomatsu, T. A novel method for the separation of bis(alpha-hydroxyalkyl)phosphinic acid diastereoisomers via formation of novel cyclic phosphinic acids. J. Org. Chem. 2006, 71, 6604-6606.

Korpiun, O.; Lewis, R. A.; Chickos, J.; Mislow, K. Synthesis and absolute configuration of optically active phosphine oxides and phosphinates. J. Am. Chem. Soc. 1968, 90, 4842-4846.

Lukeš, I.; Kotek, J.; Vojtí̌̌ek, P.; Hermann, P. Complexes of tetraazacycles bearing methylphosphinic/phosphonic acid pendant arms with copper(II), zinc(II) and lanthanides(III). A comparison with their acetic acid analogues. Coord. Chem. Rev. 2001, 216-217, 287-312.

Lutter, M.; Jurkschat, K. Aryl(dimethylaminomethyl)phosphinic acid esters. syntheses, structures, and reactions with halogen hydrogen acids, tin halides and trimethyl halosilanes. Eur. J. Inorg. Chem. 2018, manuscript accepted.

Macrae, C. F.; Edgington, P. R.; McCabe, P.; Pidcock, E.; Shields, G. P.; Taylor, R.; Towler, M.; van de Streek, J. Mercury: visualization and analysis of crystal structures. J. Appl. Cryst. 2006, 39, 453-457.

Macrae, C. F.; Bruno, I. J.; Chisholm, J. A.; Edgington, P. R.; McCabe, P.; Pidcock, E.; Rodriguez-Monge, L.; Taylor, R.; van de Streek, J.; Wood, P. A. Mercury CSD 2.0 - new features for the visualization and investigation of crystal structures. J. Appl. Cryst. 2008, 41, 466-470.

Maier, L. Organic phosphorus compounds 101. Preparation and physical properties of bis(aminoalkyl)phosphinic acids. Phosphorus, Sulfur Silicon Relat. Elem. 1992, 66, 67-72.

Onyido, I.; Albright, K.; Buncel, E. Catalysis of the ethanolysis of aryl methyl phenyl phosphinate esters by alkali metal ions: transition state structures for uncatalyzed and metal ioncatalyzed reactions. Org. Biomol. Chem. 2005, 3, 1468-1475.

Ševčík, R.; Vaněk, J.; Lubal, P.; Kotková, Z.; Kotek, J.; Hermann, P. Formation and dissociation kinetics of copper(II) complexes with tetraphosphorus acid DOTA analogs. Polyhedron 2014, 67, 449-455.

Sheldrick, G. A short history of SHELX. Acta Cryst. 2008, A64, 112-122.

Sheldrick, G. M. Crystal structure refinement with SHELXL. Acta Cryst. 2015, C71, 3-8. 